CrossMark \& click for updates

Cite this: J. Mater. Chem. B, 2016, 4, 4605

Received 30th March 2016,

Accepted 8th June 2016

DOI: $10.1039 / c 6 t b 00795 c$

www.rsc.org/MaterialsB

\section{Catalytic supramolecular self-assembled peptide nanostructures for ester hydrolysis $\dagger$}

\author{
Gulcihan Gulseren, Mohammad Aref Khalily, Ayse B. Tekinay and Mustafa O. Guler*
}

Essential amino acids in catalytic sites of native enzymes are important in nature inspired catalyst designs. Active sites of enzymes contain the coordinated assembly of multiple amino acids, and catalytic action is generated by the dynamic interactions among multiple residues. However, catalysis studies are limited by the complex and dynamic structure of the enzyme; and it is difficult to exclusively attribute a given function to a specific residue. Minimalistic approaches involving artificial catalytic sites are promising for the investigation of the enzyme function in the absence of non-essential protein components, and self-assembling peptide nanostructures are especially advantageous in this context. Here we demonstrate the design and characterization of an enzyme-mimetic catalytic nanosystem presenting essential residues (Ser, His, Asp). The function of each residue and its combinations on the nanostructures in hydrolysis reaction was studied. The catalytic self-assembled nanostructures were used for efficient ester hydrolysis such as a model substrate (pNPA) and a natural substrate (acetylcholine) highlighting the key role of self-assembly in catalytic domain formation to test the efficiency of the de novo designed catalyst as a catalytic triad model.

\section{Introduction}

Enzyme-like synthetic systems designed by the identification of evolutionarily conserved domains or computational optimization are highly promising for the development of novel catalytic materials in medicine and in industrial chemistry. ${ }^{1}$ The design of enzyme mimetic catalysts is complicated because of the complex three-dimensional conformations of proteins. An enzyme active site is composed of several amino acid residues with optimal three dimensional arrangements. Functional cooperative residues can only be determined after testing large numbers of possible peptide sequences and heavy computation., ${ }^{2,3}$ Reductionist approaches are helpful in order to reduce the workload associated with the complicated nature of proteins.

Novel strategies based on small organic molecules, supramolecular structures, polymers and inorganic materials resulted in a remarkable expansion of the field of enzyme mimics or artificial enzymes. ${ }^{1,4-9}$ Although these strategies are effective in terms of catalytic efficiency, their covalently constructed hydrolytic modules have still not advanced enough to design enzyme-like structures, since genuine enzymes fold into their active and dynamic conformation by self-assembly mechanisms. In this context,

Institute of Materials Science and Nanotechnology, National Nanotechnology Research Center (UNAM), Bilkent University, Ankara, 06800, Turkey.

E-mail: moguler@unam.bilkent.edu.tr; Fax: +90 312266 4365; Tel: +903122908986

$\dagger$ Electronic supplementary information (ESI) available: Experimental details are provided. See DOI: 10.1039/c6tb00795c self-assembling peptide molecules are considered as promising candidates for designing artificial biocatalysts due to their dynamic nature, which can be used to closely approximate the flexible and hydrophobic pockets found in natural enzymes. In addition, the self-assembled nanofibers are composed of amino acid sequences, which can be derived directly from the peptide sequences found in the enzyme active sites, thereby preserving the function of enzymes in a simpler system than proteins. The peptides are considered as "scaled-down" proteins that preserve the function while eliminating noncatalytic bulk and their use may allow a greater understanding of the structure, activity and active residue preferences of enzymatic sites. ${ }^{10-15}$

The self-assembling peptide amphiphile (PA) molecules exhibit several features similar to natural proteins; in particular, their noncovalent interaction-driven assembly (hydrogen bonding, electrostatic interactions, hydrophobic forces etc.), dynamic molecular structure, hydrophobic nanodomains and activity under natural conditions ( $\mathrm{pH}$, aqueous medium) are all similar to naturally occurring enzymes. ${ }^{16}$ Moreover, their stability, low cost, multivalent presentation on a concise area, ease of synthesis and modification, biocompatibility and ability to present multiple active domains in small areas all enhance their ability to serve as effective enzymatic catalysts. ${ }^{17}$ In addition, selfassembled peptide nanofibers can be utilized as "proto-enzymes" that provide minimalist frameworks for catalysis studies, reducing much of the complexity that is inherent to natural enzymes. ${ }^{8-12}$ So far, significant effort has been made to develop peptide 

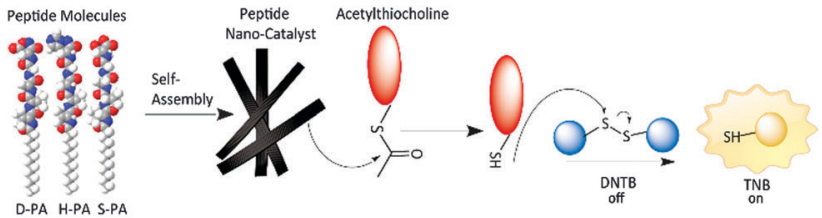

Scheme 1 Illustration of the catalytic unit assembly and hydrolysis of pNPA and acetylthiocholine substrates. Detection of the hydrolytic capability of peptide nanostructures with Ellman's reagent, and quantitative and qualitative exhibition of catalytic reaction.

designs capable of acting as high-efficiency catalysts or models for understanding the factors involved in the catalytic action. ${ }^{10,11,13,14}$ Many of these self-assembled peptide nanostructures focus on the use of single molecule as a nucleophilic site, and utilize variations on a core peptide sequence to investigate the effect of the residue identity on enzymatic catalysis.

Here we show a multivalent self-assembled nanocatalyst for catalytic action through the synergistic behaviour of three separate units; each is naturally present in the catalytic triad of the enzymes (Scheme 1). The catalytic triad (CT) containing serine, aspartate and histidine amino acid residues is the model active site for several enzymes. ${ }^{18}$ These three residues cooperate to generate a catalytic action and this cooperation mechanism makes the CT an attractive catalytic system. To generate an artificial catalytic triad, each active residue in the CT (D, H, S) was incorporated separately into a self-assembling peptide domain (Lauryl-VVAG-) that is able to assemble into $\beta$-sheet conformations through noncovalent interactions (Fig. 1 and Fig. S1, ESI $\dagger$ ). Combinations of the active amino acids were utilized in the peptide amphiphile nanostructure formation. By conjugating a single amino acid to each peptide unit, we provide flexibility to the active site chains, thereby supporting the catalytic pocket formation, which is assembled with the help of physical interactions among amino acids. The system is able to closely mimic the flexibility of the natural enzymatic triads. The catalytic triads typically are present in the hydrophobic pockets of the enzymes, and the peptide nanofiber can create hydrophobic domains intrinsically. The efficiency of the
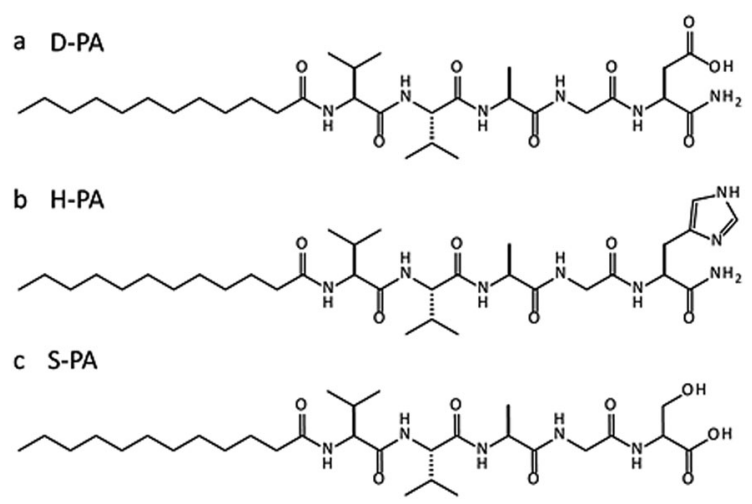

Fig. 1 Chemical structures of the peptides used to form catalytic nanostructures: (a) Lauryl-VVAGD-Am (D-PA), (b) Lauryl-VVAGH-Am (H-PA) and (c) Lauryl-VVAGS (S-PA). catalytic nanostructures was studied with a model substrate $p$-nitrophenyl phosphate (pNPA) and acetylcholine, which is a natural substrate of acetylcholine esterase. The hydrolysis of the model and natural substrate was achieved with the peptidebased artificial enzyme system in high efficiency.

\section{Experimental section}

\section{Synthesis and characterization of peptide molecules}

The peptides were synthesized using standard Fmoc (9-fluorenylmethoxycarbonyl) solid phase synthesis (Fig. 1). Protected amino acids, MBHA Rink Amide Resin, Wang Resin and HBTU (O-benzotriazole- $N, N, N, N^{\prime}$-tetramethyl-uronium-hexafluorophosphate) were purchased from Novabiochem, and lauric acid was purchased from Merck. Serine-loaded Wang resin (FmocSer-(OtBu)) or Rink amide MBHA resin was used for peptide synthesis. For each coupling reaction, Fmoc groups were removed by shaking resins in $20 \%$ piperidine in $N, N$ dimethylformamide (DMF) for $20 \mathrm{~min}$. All amino acids were activated by adding 2 molar equivalents of amino acid to 1.95 equivalents of $O$-benzotriazole- $N, N, N^{\prime}, N^{\prime}$-tetramethyl-uroniumhexafluoro-phosphate (HBTU) and dissolving the mixture in $10 \mathrm{~mL}$ of DMF. After the complete dissolution of the amino acid and HBTU in DMF, 3 molar equivalents of $N$-ethyldiisopropylamine (DIEA) were added to the solution. Each coupling reaction was performed for $2.5 \mathrm{~h}$. Lauric acid was coupled to the peptide's N-terminal. Peptide cleavage and the removal of the protecting groups were performed with $95: 2.5: 2.5$ trifluoroacetic acid (TFA): triisopropylsilane (TIS): water for $2.5 \mathrm{~h}$ at room temperature. TFA was then rotaryevaporated, ice-cold diethyl ether was added to the residue, and the resulting solution was left at $-20{ }^{\circ} \mathrm{C}$ overnight. The pellet was collected, dissolved in deionized $\mathrm{H}_{2} \mathrm{O}$ and freeze-dried. After freeze-drying, peptides were dissolved in $1 \mathrm{mM} \mathrm{HCl}$ solution in order to remove excess TFA, freeze dried again and characterized by LC-MS. An Agilent Technologies 6530 AccurateMass Q-TOF LC-MS equipped with a Zorbax SB-C8 column was used for LC-MS analysis. The concentration of the sample was $0.5 \mathrm{mg} \mathrm{mL} \mathrm{m}^{-1}$. The mobile phase was water (containing $0.1 \%$ formic acid for positively charged peptides and $0.1 \%$ ammonium hydroxide for negatively charged peptides) and acetonitrile (containing $0.1 \%$ formic acid for positively charged peptides and $0.1 \%$ ammonium hydroxide for negatively charged peptides). LC-MS analysis was run for 20 min for each sample. Each run was started with $2 \%$ acetonitrile and $98 \% \mathrm{H}_{2} \mathrm{O}$ for 5 min, and the acetonitrile content was gradually increased to $100 \%$ over $20 \mathrm{~min}$.

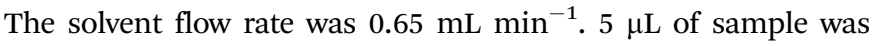
injected for each run (Fig. S1, ESI†).

\section{Circular dichroism}

Secondary structures of peptide nanofibers (pPA) were analysed using a JascoJ-815 circular dichroism spectrometer. $2 \mathrm{mM}$ peptide solutions were prepared in $\mathrm{ddH}_{2} \mathrm{O}$ with $\mathrm{pH}$ adjustment by using $\mathrm{NH}_{4} \mathrm{OH}$, coassembled by mixing and kept at room temperature in order to achieve a complete assembly. Peptide nanostructures were 

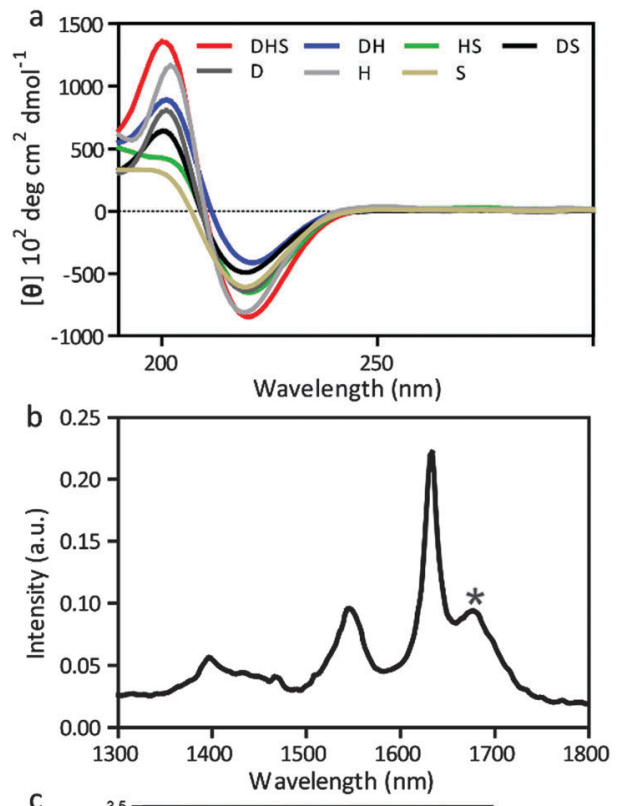

C

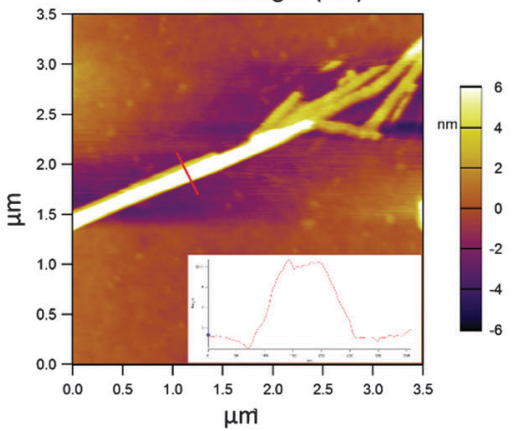

Fig. 2 Characterization of the secondary structures of the nanostructures. (a) Circular dichroism analysis of the self-assembled peptide nanostructures. (b) FTIR spectrum of the $D / H / S$ peptide nanostructure, and (c) AFM image of the co-assembled D/H/S nanostructures.

then diluted with water and the circular dichroism (CD) spectra of $1 \times 10^{-4} \mathrm{M}$ peptide solutions were recorded from $300 \mathrm{~nm}$ to $190 \mathrm{~nm}$ with a data pitch of 0.1 , a scanning speed of $100 \mathrm{~nm}$ $\min ^{-1}$, a band width of $1 \mathrm{~nm}$ and a D.I.T. of $4 \mathrm{~s}$. An average of three measurements was used for each sample, and water was used as a baseline. Peaks indicating $\beta$-sheet formation were observed in the CD spectral analysis (Fig. 2).

\section{Atomic force microscopy}

AFM sample preparation was performed by using the same samples prepared for CD measurements. Samples were diluted with water to drop-cast onto a cover glass and kept at room temperature for drying. Aggregates were measured via tapping mode in air. A commercial microscope (MFP3D, Asylum Research) was used in the measurements.

\section{Fourier transform infrared spectroscopy}

$2 \mathrm{mM}$ of solutions were prepared separately at $\mathrm{pH} 8$ on glass surfaces placed in a 24 well-plate. The plate was immersed in liquid nitrogen to obtain flash-frozen gels, which were then lyophilized for dehydration and to preserve their architectural integrity. Dried aggregates were weighed and mixed with $\mathrm{KBr}$ powder at a ratio of $1: 100(\mathrm{w} / \mathrm{w}) . \mathrm{KBr} /$ peptide mixtures were homogenized and $\mathrm{KBr}$ pellets were prepared. FTIR analysis of the samples was carried out using a Bruker VERTEX 70 with a Hyperion scanning microscope in a range of $300-4000 \mathrm{~cm}^{-1}$.

\section{Transmission electron microscopy}

$2 \mathrm{mM}$ peptide solutions were prepared and their $\mathrm{pH}$ was adjusted prior to TEM analysis. The peptide solutions were diluted in water and a small amount of solution was dropped onto a carbon-covered copper grid. 2\% (w/v) uranyl acetate solution was used to stain the peptide nanostructures. A FEI Tecnai G2 F30 transmission electron microscope was used to image the peptide nanostructures (Fig. 3, Fig. S2 and S3, ESI $\dagger$ ).

\section{Determination of the catalytic activity of the peptides}

$2 \mathrm{mM}$ peptide solutions (or amino acid solutions) were prepared and diluted to $0.1 \mathrm{mM}$ by using PBS. A $100 \mathrm{mM}$-nitrophenyl acetate pNPA substrate stock solution was prepared in DMSO and mixed with the peptide solutions in concentrations ranging from $0.5 \mathrm{mM}$ to $4 \mathrm{mM}$. For single concentration rate comparison experiments $1 \mathrm{mM}$ substrate and $0.1 \mathrm{mM}$ peptide catalysts triple, dual or single combinations - were used (Fig. 4). Immediately following mixing, kinetic measurements were performed by collecting the absorbance spectrum of the resulting $p$-nitrophenyl acetate (pNP) solution at $410 \mathrm{~nm}$ using a microplate reader. Reaction rates were calculated for each concentration with an extinction coefficient of $10166 \mathrm{M}^{-1} \mathrm{~cm}^{-1}$ and fitted into the Michaelis-Menten equation $\left(v_{0}=k_{\text {cat }}[\mathrm{E}]_{\mathrm{o}}[\mathrm{S}]_{\mathrm{o}} /\left(K_{\mathrm{M}}+\left[\mathrm{S}_{0}\right]\right)\right)$ (Fig. S6, ESI $\dagger$ ).

\section{Acetylthiocholine hydrolysis experiments}

$100 \mathrm{mM}$ stock solutions of acetylthiocholine and 5,5-dithiobis(2nitrobenzoic acid) DTNB were prepared in DMSO, and peptide solutions were diluted to $0.1 \mathrm{mM}$ in PBS. $2 \mu \mathrm{L}$ of DTNB and

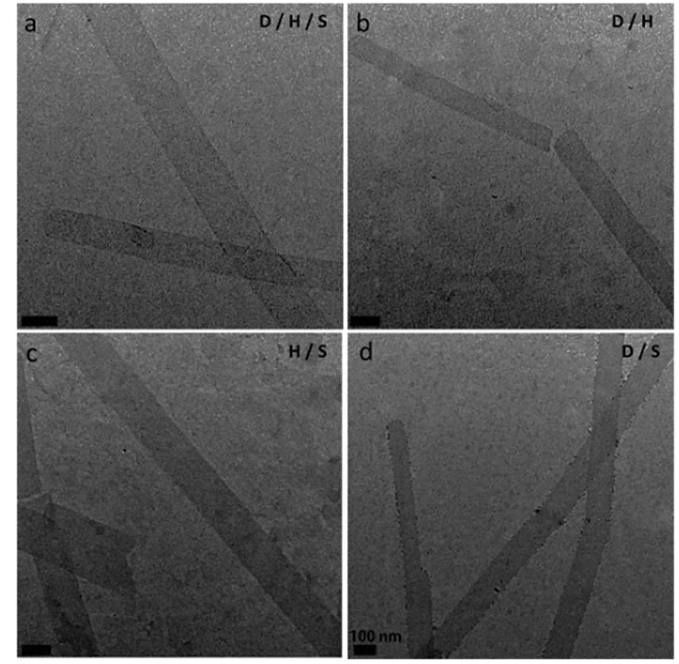

Fig. 3 TEM images of the peptide nanostructures: (a) D/H/S (D-PA + $\mathrm{H}-\mathrm{PA}+\mathrm{S}-\mathrm{PA}),(\mathrm{b}) \mathrm{D} / \mathrm{H}(\mathrm{D}-\mathrm{PA}+\mathrm{H}-\mathrm{PA}),(\mathrm{c}) \mathrm{H} / \mathrm{S}(\mathrm{H}-\mathrm{PA}+\mathrm{S}-\mathrm{PA})$ and (d) D/S (D-PA + S-PA). Scale bar: $100 \mathrm{~nm}$. 

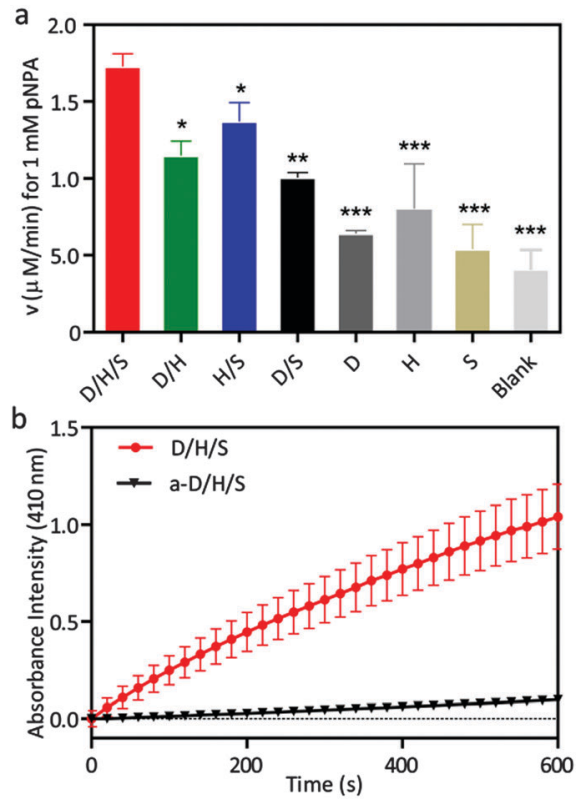

Fig. 4 Catalytic reaction rates of (a) peptide combinations for pNPA hydrolysis, and (b) D/H/S peptide nanostructure vs. soluble amino acid (a-D/H/S) (L-aspartic acid, L-histidine and L-serine) mixture. (Mean $\pm \mathrm{SEM}$, $n \geq 3$ measurements per sample, one-way analysis of variance (ANOVA) ${ }^{*} p<0.05,{ }^{* *} p<0.01$, and ${ }^{* *} p<0.0001$ ).

acetylthiocholine were then added in sequential order to the reaction mixture. Immediately after substrate addition, absorbance data were collected at $405 \mathrm{~nm}$ and converted to reaction rates by using a nominal extinction coefficient of $13600 \mathrm{M}^{-1} \mathrm{~cm}^{-1}$.

\section{Tracking of acetylcholine hydrolysis by mass spectrometry}

An Agilent Technologies 6224 Accurate-Mass TOF LC-MS equipped with an Intersil Diol $4.6 \times 250 \mathrm{~mm}$ column was used for LC-MS analysis. Initial acetylcholine and peptide concentrations were $5 \mathrm{mM}$ and $0.02 \mathrm{mM}$, respectively. The mobile phase was ammonium formate $(15 \mathrm{mM}, \mathrm{pH} 3.5)$ and acetonitrile $(10: 90 \mathrm{v} / \mathrm{v})$. LC-MS was run for $25 \mathrm{~min}$ for each sample. Each run was performed under a stable gradient and with a flow rate of $0.06 \mathrm{~mL} \mathrm{~min}{ }^{-1}$.

\section{Results and discussion}

\section{Self-assembled peptide nanostructures}

A functional peptide nanostructure library was designed and screened to understand the role of amino acids in the formation of a catalytic triad as an artificial enzyme mimetic system. The peptide amphiphile molecules functionalized with amino acid residues (aspartic acid, histidine and serine) were used to form catalytic nanofibers (Fig. 1 and Fig. S1, ESI $\dagger$ ).

Individual peptide self-assemblies and their coassemblies were studied by circular dichroism (CD) spectroscopy. The peptides and co-assembled mixtures were incubated for $12 \mathrm{~h}$ in order to reach an equilibrium state for hydrophobic collapse and hydrogen bonding interaction. The prepared peptide nanocatalysts were dissolved in aqueous media and they showed a major negative peak around $220 \mathrm{~nm}$ in the $\mathrm{CD}$, which is attributed to the formation of a $\beta$-sheet secondary structure ${ }^{19}$ (Fig. 2a). Fourier transform infrared (FTIR) spectra also showed an amide peak at around $1633 \mathrm{~cm}^{-1}$ accompanied by a broad band at $1681 \mathrm{~cm}^{-1}$, indicating the hydrogen bonding and secondary structure characteristics of nanostructures (Fig. $2 \mathrm{~b}$ and Fig. S5, ESI $\dagger$ ). ${ }^{20,21}$ This observation is in agreement with the imaging results, as nanostructures are typically formed by $\beta$-sheets. ${ }^{16}$ The width of the nanostructures was about $100-200 \mathrm{~nm}$ by TEM and by atomic force microscopy (AFM) (Fig. 2c and Fig. S2-S4, ESI $\dagger$ ). AFM demonstrated the flat morphology of the nanostructures and revealed the height of the nanostructures at about $6 \mathrm{~nm}^{22,23}$ (Fig. 2c). TEM analysis was performed to observe the morphology of the self-assembled peptide nanostructures. For all peptide combinations $(\mathrm{D} / \mathrm{H} / \mathrm{S}, \mathrm{D} / \mathrm{H}, \mathrm{H} / \mathrm{S}$ and $\mathrm{D} / \mathrm{S})$, nanostructures were formed under the aqueous conditions (Fig. 3). The high aspect ratio nanostructures were observed through the self-assembly of short peptide molecules, resulting in a wide supramolecular structure. ${ }^{24}$ Strong driving forces, such as electrolytes, high peptide concentrations, $\mathrm{pH}$, and concentration, are generally exploited to produce nanostructures. ${ }^{25,26}$ The peptide length is also an important contributor during nanostructure architecture formation and short peptides have shown higher tendency to display wide nanostructure growth. ${ }^{27}$ In our study, the use of short peptides to form a nanostructure was observed to cause the enlargement of all structural widths and result in the formation of high surface area nanostructures through lateral growth.

\section{Catalytic activity of the peptide nanostructures}

The structure and the mechanism of action of catalytic peptide nanostructures were studied. Peptide nanocatalysts are easy to produce and modify, which makes them ideal materials for understanding the individual and cooperative functions of amino acids in the catalytic pockets of enzymes. Peptide amphiphile nanocatalysts can be designed with histidine residues as catalytic domains. ${ }^{10-12}$ Here we show an artificial enzyme mimetic nanocatalyst with multiple reactive units, which can emulate the catalytic triad. Accordingly, each active residue is presented on the peptide nanostructure, and hydrolytic sites are formed through the peptide self-assembly, a process that resembles the natural enzyme folding mechanism. The mixtures of peptides were investigated to determine the function of each reactive residue during ester hydrolysis reaction. The catalytic properties of the peptide nanostructures were analysed by using $p$-nitrophenyl acetate (pNPA), a common model substrate for esterase activities. Autohydrolysis of pNPA was demonstrated as a blank and the hydrolytic activity of peptide groups was studied. The reaction rates associated with enzyme catalysis for single, binary and triple peptide combinations were studied (Fig. 4a). The $\mathrm{D} / \mathrm{H} / \mathrm{S}$ PA nanostructure was found to be the most active system for pNPA hydrolysis, followed by the dual combinations $\mathrm{H} / \mathrm{S}$, $\mathrm{D} / \mathrm{H}$ and D/S PAs. Single functional group peptide nanostructures were generally ineffective because these systems are unable to establish the intermolecular associations required for molecular coordination; however, H-PA was observed to exhibit catalytic activity due to its nucleophilic nature at neutral $\mathrm{pH}$. This result was found to be similar to previous observations, in which covalently 
conjugated histidine moieties have shown upgraded hydrolysis activity. ${ }^{10,11}$

The assembly of active residues and cooperation among residues whose units displayed on a confined area have been found to be significant for the enhancement of catalytic action. ${ }^{10-13}$ The significance of the assembly in catalytic action was tested using soluble amino acids (L-aspartic acid, L-histidine and $\mathrm{L}$-serine) and these residues were mixed by using the same preparation method that was used to prepare peptide nanostructures (Fig. 4). The soluble amino acid mixture (D/H/S) has not revealed significant hydrolysis activity for pNPA hydrolysis and this result indicated the importance of cooperativity of the reactive groups to generate catalytic action. In addition to the active sites, the $\mathrm{E} / \mathrm{K}$ nanofiber system containing glutamic acid and lysine residues was used as a control. The $\mathrm{E} / \mathrm{K}$ nanofibers had catalytic activity much lower than the $\mathrm{D} / \mathrm{H} / \mathrm{S}$ peptide system, suggesting that amino acid composition indeed plays a critical role in catalytic activity (Fig. S7, ESI $\dagger$ ).

The catalytic activity of $\mathrm{D} / \mathrm{H} / \mathrm{S}, \mathrm{H} / \mathrm{S}, \mathrm{D} / \mathrm{H}$ and $\mathrm{D} / \mathrm{S}$ residues on the PA nanostructures was characterized and all of the nanostructures were found to display measurable activity (PBS buffer at $\mathrm{pH}$ 7), and exhibited a substrate concentration-initial rate of reaction dependencies consistent with the Michaelis-Menten model (Table 1 and Fig. S6, ESI $\dagger$ ). The catalytic activity was mainly caused by all three residues. The $\mathrm{D} / \mathrm{H} / \mathrm{S}$ supramolecular nanostructures were found to be the most active, exhibiting the highest catalytic efficiency at $k_{\text {cat }} / K_{\mathrm{M}}=126.62 \pm 14.58 \mathrm{M}^{-1} \mathrm{~s}^{-1}$. The catalytic efficiency of $\mathrm{D} / \mathrm{H} / \mathrm{S}$ nanofibers was at least 4-times higher than those of dual systems, suggesting that all three amino acids are required for complete catalytic action. $\mathrm{D} / \mathrm{H} / \mathrm{S}$ also exhibited a stronger binding affinity to the substrate, because its binding constant, $K_{\mathrm{M}}$, was the lowest among all the groups $\left(K_{\mathrm{M}}=0.035 \mathrm{mM}\right)$.

The chemical nature of the active residues provides a better understanding of the reaction mechanism. During the enzymatic action, the aspartate group facilitates histidine group's capacity as a proton acceptor. The deprotonated imidazole moiety recruits a proton from the hydroxyl side chain of the serine, creating a highly nucleophilic alkoxide group on the serine residue. ${ }^{18}$ The catalytic triad and nucleophile generation by histidine and serine residues is important for the enzyme activity. ${ }^{28,29}$ Our observations are in agreement with the common mechanism, as the H/S nanofiber system was observed to have the second-best reaction efficiency $\left(k_{\mathrm{cat}} / K_{\mathrm{M}}=35.90 \pm 4.61 \mathrm{M}^{-1} \mathrm{~s}^{-1}\right)$. Previous studies have also indicated the significance of cooperation of each residue and especially the histidine-serine pair should act together to generate nucleophilic activity. ${ }^{28,30}$ The absence of the aspartate residue in

Table 1 Catalytic activity of designed triad and dual peptide nanostructure combinations at $\mathrm{pH} 7.4$ in $1 \times$ PBS buffer

\begin{tabular}{lcll}
\hline & $k_{\text {cat }} / K_{\mathrm{M}}\left(\mathrm{M}^{-1} \mathrm{~s}^{-1}\right)$ & $k_{\text {cat }} \times 10^{-3}\left(\mathrm{~s}^{-1}\right)$ & $K_{\mathrm{M}}(\mathrm{mM})$ \\
\hline $\mathrm{D} / \mathrm{H} / \mathrm{S}$ & $126.62 \pm 14.58$ & $4.41 \pm 0.51$ & 0.035 \\
$\mathrm{H} / \mathrm{S}$ & $35.90 \pm 4.61$ & $2.60 \pm 0.33$ & 0.072 \\
$\mathrm{D} / \mathrm{H}$ & $8.97 \pm 1.43$ & $2.59 \pm 0.42$ & 0.289 \\
$\mathrm{D} / \mathrm{S}$ & $7.63 \pm 1.69$ & $1.12 \pm 0.25$ & 0.148
\end{tabular}

the $\mathrm{H} / \mathrm{S}$ binary system decreased the proton accepting capability of histidine, leading to impairments in the formation of an alkoxide group. However, the complex nevertheless retained its capacity to catalyse pNPA, and exhibited only a minor decrease in binding affinity $\left(K_{\mathrm{M}}=0.072 \mathrm{mM}\right)$.

The serine residue is responsible for both recruiting the enzyme substrate and performing the hydrolytic attack during catalytic action, ${ }^{18}$ and forms tetrahedral intermediates that are involved in both functions. The kinetics result of $\mathrm{D} / \mathrm{H}$ suggests that the exclusion of serine results in greatly reduced catalytic action $\left(k_{\text {cat }} / K_{\mathrm{M}}=8.97 \pm 1.43 \mathrm{M}^{-1} \mathrm{~s}^{-1}\right)$, and the binding affinity of $\mathrm{D} / \mathrm{H}$ was likewise lower compared to serine-containing groups. These results are in accordance with the previous findings about the catalytic triad. In addition, comparisons between the catalytic activities of D/S and H/S systems suggest that the function of serine is highly dependent on histidine. The serine-mediated catalysis is greatly inhibited in the absence of the histidine residue. The reaction efficiency of $\mathrm{D} / \mathrm{S}$ was $k_{\mathrm{cat}} / K_{\mathrm{M}}=7.63 \pm 1.69 \mathrm{M}^{-1} \mathrm{~s}^{-1}$, which is lower than that of $\mathrm{D} / \mathrm{H} / \mathrm{S}$ and $\mathrm{H} / \mathrm{S}$ systems. The catalytic efficiency of $\mathrm{D} / \mathrm{S}$ is also lower than that of the $\mathrm{D} / \mathrm{H}$ system because of the ability of aspartate to enhance the nucleophilic character of histidine but not serine. In addition, histidine itself is a good nucleophile under basic conditions ${ }^{10,11}$ allowing it to perform hydrolysis without support from other residues.

\section{Acetylcholine esterase-like activity}

Acetylcholinesterase is a hydrolase that releases choline from the neurotransmitter acetylcholine during neurotransmission, and possesses an esterase unit that acts like a serine protease and contains a catalytic triad. Inspired by the possibility of replacing the function of a natural enzymatic system with an artificial catalytic peptide nanofiber, we utilized acetylcholine as a model ester for studying the catalytic effect of the dual and triple functionalized nanofiber combinations. We studied hydrolysis of acetylcholine by mass spectrometry (Fig. S8, ESI $\dagger$ ).

Acetylthiocholine (ATCh) was exploited as an acetylcholine analogue for spectrometric tracking, and it is chemically similar to acetylcholine in terms of hydrolysis reaction except for the presence of an additional thiol group. After hydrolysis, released thiol groups remain on the choline residues and they can be monitored by Ellman's assay, ${ }^{31}$ which is a commonly used method as a colorimetric enzyme assay. This technique is based on the reaction between 5,5-dithiobis(2-nitrobenzoic) acid (DTNB) and thiol groups on thiocholine (TCh), which is released after the cleavage (Fig. 5). Consistent with our previous results, serine protease-like peptide nanostructures were found to be applicable for the catalysis of ester containing natural substrates. The $\mathrm{D} / \mathrm{H} / \mathrm{S}$ peptide nanocatalyst exhibited the highest catalytic rate. Catalytic activities of each combination were also in agreement with results acquired from model substrate pNPA (Fig. 5 and Fig. S9, ESI $\dagger$ ), as D/H and $\mathrm{H} / \mathrm{S}$ displayed less activity for acetylcholine and $\mathrm{D} / \mathrm{S}$ was the least active catalyst combination, reflecting the importance of the serine and histidine residues during hydrolysis. 


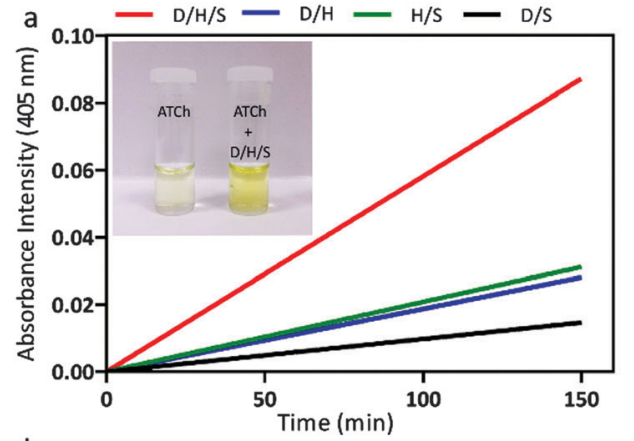

b

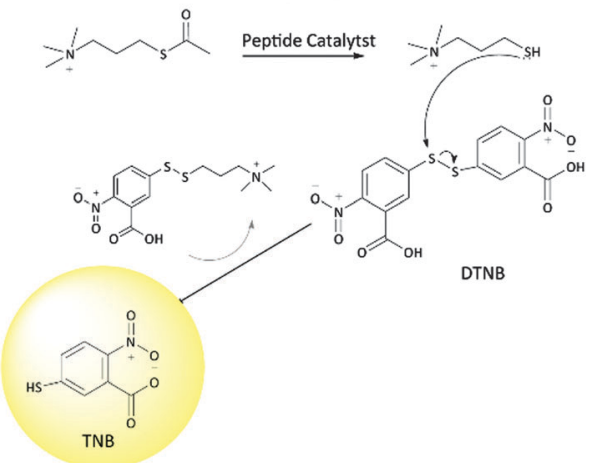

Fig. 5 (a) Comparison of catalytic reaction rates of all peptide combinations for acetylthiocholine. (b) Reaction mechanism with Ellman's reagent after the hydrolysis of acetylthiocholine.

\section{Conclusions}

In this work, the self-assembled peptide nanostructures containing chemically active groups on a high-surface area were utilized for hydrolysis of model esters. A noncovalent selfassembly method was utilized to form the nanostructures capable of mimicking the structure and the function of the catalytic triad presented in the esterase active site. The roles of individual amino acids were elucidated in the catalytic nanostructure system. We demonstrated the mechanisms of complex enzymatic reactions by using a peptide nanostructure system. The catalytic triad model created on the nanostructures was investigated through the assembly of combinations of reactive amino acid residues. Both natural and synthetic ester containing substrates were used to demonstrate the synergy between the catalytic units. The multivalent nanostructures shown here are promising for the investigation of enzyme functionality, developing artificial enzymes and also for designing multifunctional systems. Potentially, by altering the chemical content of the self-assembling molecules, multifunctional bioactive enzyme mimetic nanostructures can be produced.

\section{Acknowledgements}

This work was funded by TUBITAK Grant number 112 T602 and the BIDEB PhD fellowship. M. O. G. and A. B. T. acknowledge support from the Turkish Academy of Sciences Distinguished Young Scientist Award (TUBA-GEBIP). We thank M. Guler for
TEM imaging, A. E. Topal for his help in AFM measurements and A. D. Ozkan for fruitful discussions.

\section{References}

1 Y. Murakami, J. Kikuchi Ji, Y. Hisaeda and O. Hayashida, Chem. Rev., 1996, 96, 721-758.

2 G. Kiss, N. Celebi-Olcum, R. Moretti, D. Baker and K. N. Houk, Angew. Chem., 2013, 52, 5700-5725.

3 A. Zanghellini, Curr. Opin. Biotechnol., 2014, 29, 132-138.

4 R. Breslow and S. D. Dong, Chem. Rev., 1998, 98, 1997-2012.

5 C. Douat-Casassus, T. Darbre and J. L. Reymond, J. Am. Chem. Soc., 2004, 126, 7817-7826.

6 A. Clouet, T. Darbre and J. L. Reymond, Angew. Chem., 2004, 43, 4612-4615.

7 M. Resmini, Anal. Bioanal. Chem., 2012, 402, 3021-3026.

8 Y. Lin, J. Ren and X. Qu, Adv. Mater., 2014, 26, 4200-4217.

9 D. Astruc, F. Lu and J. R. Aranzaes, Angew. Chem., 2005, 44, 7852-7872.

10 M. O. Guler and S. I. Stupp, J. Am. Chem. Soc., 2007, 129, 12082-12083.

11 G. Gulseren, I. C. Yasa, O. Ustahuseyin, E. D. Tekin, A. B. Tekinay and M. O. Guler, Biomacromolecules, 2015, 16, 2198-2208.

12 C. Q. Zhang, X. D. Xue, Q. Luo, Y. W. Li, K. N. Yang, X. X. Zhuang, Y. G. Jiang, J. C. Zhang, J. Q. Liu, G. Z. Zou and X. J. Liang, ACS Nano, 2014, 8, 11715-11723.

13 M. A. Khalily, G. Gulseren, A. B. Tekinay and M. O. Guler, Bioconjugate Chem., 2015, 26, 2371-2375.

14 C. M. Rufo, Y. S. Moroz, O. V. Moroz, J. Stohr, T. A. Smith, X. Hu, W. F. DeGrado and I. V. Korendovych, Nat. Chem., 2014, 6, 303-309.

15 Z. Huang, S. Guan, Y. Wang, G. Shi, L. Cao, Y. Gao, Z. Dong, J. Xu, Q. Luo and J. Liu, J. Mater. Chem. A, 2013, 1, 2297-2304.

16 H. Cui, M. J. Webber and S. I. Stupp, Biopolymers, 2010, 94, 1-18.

17 E. Arslan, I. C. Garip, G. Gulseren, A. B. Tekinay and M. O. Guler, Adv. Healthcare Mater., 2014, 3, 1357-1376.

18 L. Hedstrom, Chem. Rev., 2002, 102, 4501-4524.

19 N. Greenfield and G. D. Fasman, Biochemistry, 1969, 8, 4108-4116.

20 S. D. Moran and M. T. Zanni, J. Phys. Chem. Lett., 2014, 5, 1984-1993.

21 B. Dai, D. Li, W. Xi, F. Luo, X. Zhang, M. Zou, M. Cao, J. Hu, W. Wang, G. Wei, Y. Zhang and C. Liu, Proc. Natl. Acad. Sci. U. S. A., 2015, 112, 2996-3001.

22 P. Moitra, K. Kumar, P. Kondaiah and S. Bhattacharya, Angew. Chem., 2014, 53, 1113-1117.

23 L. Pauling and R. B. Corey, Proc. Natl. Acad. Sci. U. S. A., 1951, 37, 729-740.

24 H. Cui, T. Muraoka, A. G. Cheetham and S. I. Stupp, Nano Lett., 2009, 9, 945-951.

25 H. Guo, J. Zhang, T. Xu, Z. Zhang, J. Yao and Z. Shao, Biomacromolecules, 2013, 14, 2733-2738. 
26 C. Guo, Y. Luo, R. Zhou and G. Wei, ACS Nano, 2012, 6, 3907-3918.

27 T. J. Moyer, H. Cui and S. I. Stupp, J. Phys. Chem. B, 2013, 117, 4604-4610.

28 M. J. Sutcliffe, I. Haneef, D. Carney and T. L. Blundell, Protein Eng., 1987, 1, 377-384.
29 M. J. Sutcliffe, F. R. Hayes and T. L. Blundell, Protein Eng., 1987, 1, 385-392.

30 E. J. Robertson, G. K. Oliver, M. Qian, C. Proulx, R. N. Zuckermann and G. L. Richmond, Proc. Natl. Acad. Sci. U. S. A., 2014, 111, 13284-13289.

31 G. L. Ellman, Arch. Biochem. Biophys., 1959, 82, 70-77. 